\title{
Celebrating the 150th anniversary of the Periodic Table: an outlook in the circular economy era
}

\author{
Giuseppe Musumarra ${ }^{1 *}$ \\ ${ }^{1}$ Dipartimento di Scienze Chimiche, Università di Catania, Catania, Italy
}

\section{Summary}

The first version of The Periodic Table elaborated by Mendeleev was published on February 17, 1869. To celebrate the 150th anniversary of this event, the United Nations declared 2019 as the International Year of the Periodic Table. This discovery was achieved as the conclusion of a long itinerary engaging several researchers investigating the periodicity in the properties of the chemical elements. In this process the Sicilian chemist Stanislao Cannizzaro provided a significant contribution. The impact of the Periodic Table on the scientific progress, as well as on the improvement of mankind life conditions and welfare, has been enormous. However, the increasing recognition of the limited resources of our planet, nowadays requires a change of paradigm from linear to circular economy. In order to tackle such a complex problem, the data reported in the traditional Periodic Table need to be integrated by information regarding the elements availability in nature, the sustainability of the processes, and the recycling possibility. Examples regarding lithium, cobalt, and rare earth elements are reported.

Keywords: Dmitri I. Mendeleev (1834-1907), Periodic Table, circular economy, cobalt, indium, lithium, neodymium.

*E-mail: gmusumarra@unict.it 


\section{Riassunto \\ La Tavola Periodica compie 150 anni: aspetti attuali nell'era della economia circolare}

La formulazione della legge di periodicità e la conseguente elaborazione della Tavola Periodica degli elementi rappresentano una pietra miliare nella storia della Scienza e dell'Uomo. In occasione del $150^{\circ}$ anniversario della pubblicazione del primo articolo di Mendeleev (1869) le Nazioni Unite hanno dichiarato il 2019 Anno Internazionale della Tavola Periodica. Tale scoperta avvenne a conclusione di un lungo processo per stabilire un criterio di classificazione degli elementi, al quale il chimico siciliano Stanislao Cannizzaro fornì un contributo determinante. La Tavola Periodica è alla base del progresso scientifico, del miglioramento delle condizioni di vita e della ricchezza nei quindici decenni successivi alla pubblicazione dell'articolo che la ha resa disponibile alla comunità scientifica. Tuttavia, lo sfruttamento delle limitate risorse naturali del pianeta pone oggi l'esigenza di un cambiamento di paradigma di sviluppo da quello di una economia lineare a quello di una economia circolare. Per affrontare scientificamente questo complesso problema in un contesto globale, ai dati riportati nella Tavola Periodica tradizionale è necessario aggiungere informazioni sulla disponibilità degli elementi nella crosta terrestre, sulla sostenibilità dei processi produttivi e sulle possibilità di riciclo. Vengono riportati esempi riguardanti il litio, il cobalto ed alcuni elementi delle terre rare.

Parole chiave: Dmitri I. Mendeleev (1834-1907), Tavola Periodica, economia circolare, cobalto, indio, litio, neodimio.

\section{Historical background}

The first version of the Periodic Table elaborated by Dmitri I. Mendeleev (18341907) was published on February 17, 1869. To celebrate the 150th anniversary of this event, the United Nations declared 2019 as the International Year of the Periodic Table. Mendeleev proposed the periodicity law of chemical elements adopting a classification criterion based on their atomic weight, a quantity which "does not refer to a substance, but to a portion of it which is common to the substance and to all its compounds [...] The atomic weight does not belong to charcoal or diamond, but rather to carbon" (Mendeleev, 1869). This discovery was achieved as the conclusion of a long itinerary covered by several researchers investigating the periodicity in the properties of the chemical elements. In this process the Sicilian chemist Stanislao Cannizzaro (1826-1910) provided a significant contribution to assess the concepts of atom and molecule. In 1858 he re-visited the Avogadro principle stating that equal volumes of different gases contain the same number of molecules, not of atoms. He then determined experimentally the molecular weight of different gases containing the same element: $\mathrm{H}\left(\mathrm{H}_{2}, \mathrm{HCl}, \mathrm{HBr}, \mathrm{HI}, \mathrm{H}_{2} \mathrm{O}, \mathrm{NH}_{3}, \mathrm{CH}_{3} \mathrm{COOH}\right), \mathrm{O}\left(\mathrm{O}_{2}, \mathrm{H}_{2} \mathrm{O}, \mathrm{CH}_{3} \mathrm{COOH}\right), \mathrm{Cl}\left(\mathrm{Cl}_{2}\right.$, $\mathrm{HCl}, \mathrm{HgCl}_{2}, \mathrm{AsCl}_{3}$ ) concluding that various quantities of the same element contained in equal volumes, either of the free elements or of its compounds, are all 
multiples of the same quantity. He defined the atom as "a constant weight which constitutes chemical compounds as entire multiples (never sub-multiples)" (Cannizzaro, 1858). The Dalton atomic weights based on an hypothesis (1803), were validated by Cannizzaro as the result of experimental data treatment defining correct atomic weights which allowed Mendeleev to envisage the elements' periodicity and to construct the Periodic Table. Cannizzaro's merits were recognised by Mendeleev himself who claimed: "I consider him as my real predecessor".

In the past 150 years the elements of the periodic Table, originally 61, increased up to 118 and scientists are presently engaged in discovering new ones. The Periodic Table represents a milestone in the development of Chemistry and is presently an icon symbol of its unity, overcoming the boundaries of science and going further to literature (Levi, 1987).

\section{The Periodic Table in the circular economy era}

Since its discovery, the impact of the Periodic Table on the scientific progress, as well as on the improvement of mankind life conditions and welfare, has been enormous. In the third millennium the increasing recognition of the limited resources of our planet focused public attention to the concept of sustainability, defined by the United Nations as "meeting the needs of the present without compromising the ability of future generations to meet their needs."

Consequently the need of a transition from a society based on mass consumption, uncontrolled waste production and heavy fossil fuels exploitation, toward a new society based on resource efficiency, new production and consumption behaviours, waste reduction re-use and recycle (the so called 3R's waste hierarchy), is gradually being recognized. This change implies a paradigm shift involving big society and institutional changes as well as the development of new technologies.

The uncontrolled disposal of vehicles and Hi-Tech devices (mobile phones, personal computers, printers, TVs, washing machines, refrigerators, lamps, photovoltaic panels and so on) prompted Europe regulations on End-of-Life Vehicles (EoLV) in 2000 (European Union, 2000) and on Waste Electrical and Electronic Equipment (WEEE) in 2006 (European Union, 2006). The world production of WEEE was 45 million tons in 2016 and is estimated to be over 52 million tons in 2021, with the fastest increasing rate in the solid urban waste (Baldé et al., 2017).

Hence the need to ban the uncontrolled disposal of these goods at the end of their life encouraging the implementation of a virtuous circular economy model where the recovered materials are used as raw materials for new production processes. In the present work a few examples of recycle and reuse of elements will be considered.

In the third millennium environmental science started tackling this issue by adopting interdisciplinary approaches with the aim to turn the above problem into a scientific, environmental, and market opportunity. In the above scenario, Chemistry and the Periodic Table play a key role. In this context, the data re- 


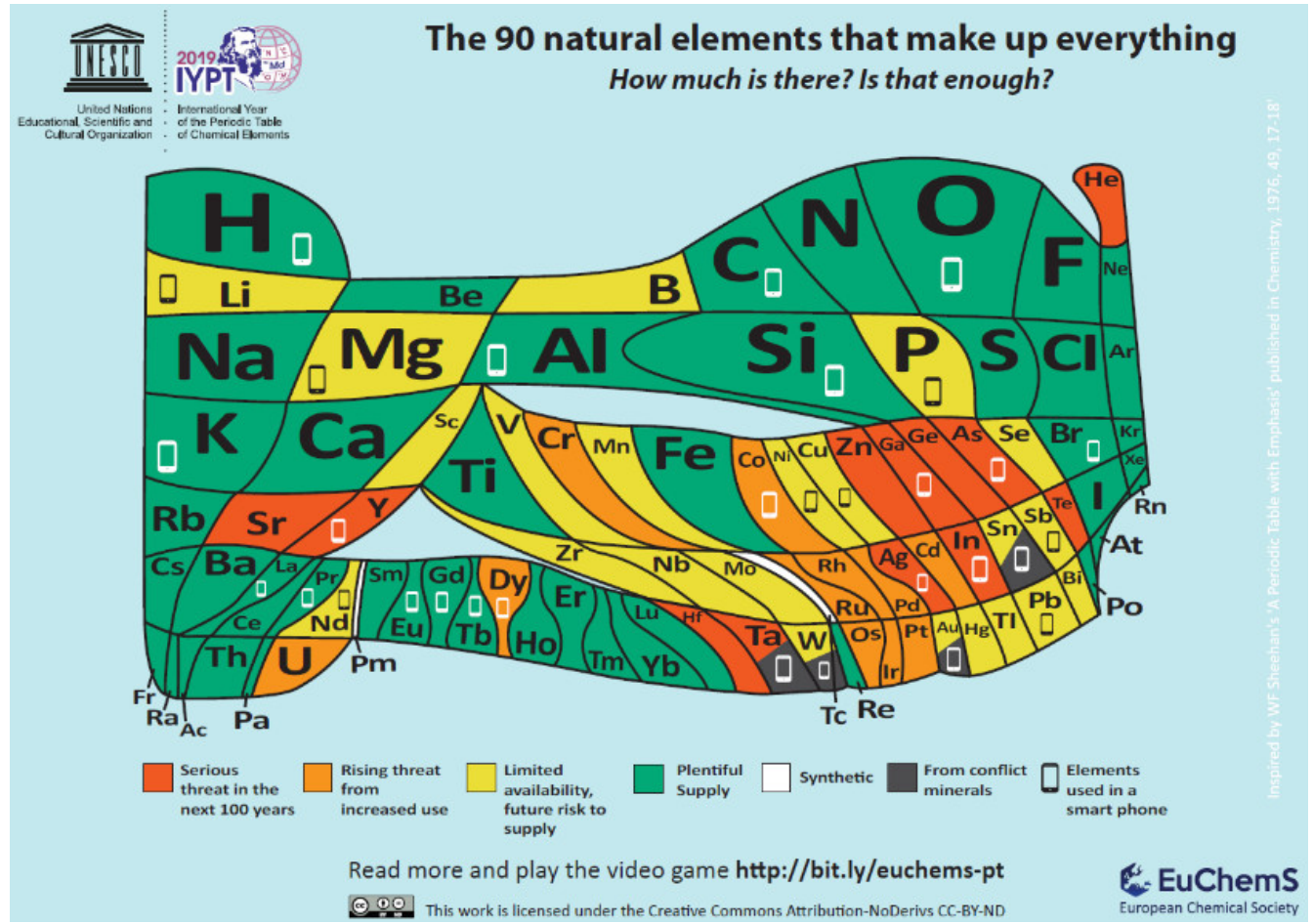

Figure 1: Present availability and supply forecasts for 90 natural elements (redrawn after European Chemical Society, 2019).

ported in the traditional Periodic Table need to be integrated by information regarding the elements availability in nature, the sustainability of the processes, and the recycling possibility. To celebrate the 150th anniversary of the Periodic Table, the Federation of the European Chemical Societies decided to donate to all their members, and to many school students, an attractive "updated" Periodic Table which can be downloaded at no charge from the European Chemical Society (2019).

In Figure 1 the present availability of 90 chemical elements is reported and an estimate of their future supply provided; furthermore, the elements present in a mobile phone are evidenced. The above Table gives an overall picture providing guidance to develop sustainable production processes for chemical compounds and Hi-Tech devices.

Herein the attention is focused on a few elements used in batteries for both electric vehicles and portable electronics, and on rare elements present in smartphones.

At the beginning of this century lithium ion batteries have been widely used in portable devices, mainly laptop computers and portable phones, due to several advantages: they are rechargeable and possess high energy density. However, the exponential increase of electric vehicles production urges the need of raw materials supply for batteries requiring much higher quantities as compared with Hi-Tech portable devices. The overall annual production of battery companies increased from 28 GWh in 2014 to 180 GWh in 2017 and is estimated to be 250 GWh in 2020 (Jaffe, 2017). 
Lithium ion batteries contain many elements, aluminium and copper foils used as current collectors, manganese, natural graphite, nickel and many others which are not expected to encounter resource shortage due to the growth in battery demand. The main concern on raw materials supply regards two elements: lithium and cobalt. In addition to the use of lithium cobalt oxide $\left(\mathrm{LiCoO}_{2}\right)$ as anode, lithium is also used as electrolyte in lithium ion batteries. Although nickel metal hydride batteries are still used in some hybrid electric vehicles, they have been replaced by lithium ion batteries for plug-in hybrid vehicles and battery electric vehicles due to their high energy density, to their low weight, and to their longer life cycle.

$\mathrm{Li}$ is the smallest alkaline metal in the first group of the Periodic Table, followed by $\mathrm{Na}, \mathrm{K}, \mathrm{Rb}, \mathrm{Cs}, \mathrm{Fr}$. It was named by Berzelius lithium (stone, from the greek "lithos") as it was discovered in a solid mineral, differently from $\mathrm{K}$ discovered in plants ash, and Na present in animal's blood. The natural abundance of $\mathrm{Li}$ in the earth crust is $20 \mathrm{mg} / \mathrm{kg}$ (20ppm, 25th element) much lower than that of $\mathrm{Na}(23600 \mathrm{ppm}$, 6th element). Li industrial use is not limited to batteries, having several applications in electronics, ceramics, metallurgy, optics, polymers, lubricants, and many others.

Lithium availability is based on different extraction technologies. It can be recovered by evaporation of the salt lakes brine or extracted from mined pegmatite, present in the mineral spodumene. In the first case the salt water is concentrated and by addition of soda a precipitate of $\mathrm{Li}_{2} \mathrm{CO}_{3}$ is recovered by filtration. In the second case the mine concentrated is leached and precipitated as $\mathrm{Li}_{2} \mathrm{CO}_{3}$. In order to estimate the future availability of an element, an important issue is the geographical distribution of its natural sources. Concentration in a single or in a few countries, especially if politically unstable and/or under the economic influence of a single giant country, is a very important factor to take into account for a reliable estimate of future global supply. Furthermore it may depend on different extraction technologies from different ores.

The main countries producing lithium are Chile and Argentina as far as brine production is concerned, and Australia for the extraction of lithium from spodumene. A minor lithium supply, obtained by both methods, is provided by China (Olivetti et al., 2017). Such a geographical distribution and the adoption of different extraction technologies suggest that lithium supply might meet the market demand in the near future. For the above reasons in the Figure lithium is reported with a yellow background, indicating limited availability and future risk to supply.

In the same Table, the situation appears definitely worse for cobalt, reported with an orange background indicating rising threat from increasing use.

Co is mainly produced as a co-product of $\mathrm{Ni}$ and $\mathrm{Cu}$ extraction ores industry, therefore its economy is strongly affected by the market of the above elements. Moreover in both ores the Co content is about one order of magnitude lower than that of $\mathrm{Ni}$ and $\mathrm{Cu}$. The Co production associated with $\mathrm{Cu}$ is concentrated in mining Co-Cu ores located in the Democratic Republic of Congo (DRC). This geographical concentration in mining is paralleled by a refining concentration 
located in China. Therefore the Co trade network is dominated by a small group of countries, including the primary link between the DRC and China (Olivetti et al., 2017). In recent years China was the world's main producer of refined Co and the leading supplier of Co imports to the United States, as well as the world's main consumer of Co, $80 \%$ of which for the rechargeable battery industry (Nansai et al., 2014).

The above considerations account for the concern relative to the global supply of Co due to its increasing use for batteries in the automotive industry. Hence recent interest in searching alternative non-cobalt containing cathodes such as $\mathrm{LiFePO}_{4}$, exhibiting high stability and high power capability but not yet competitive with $\mathrm{LiCoO}_{2}$ (Olivetti et al., 2017), or next generation lithium nickel manganese cobalt formulations (Jaffe, 2017). Other cathodes based on $\mathrm{Ni}$, Ti and Mo (Lee et al., 2015) or Nb (Yabuuchi et al., 2015) exhibiting very high energy content are currently being investigated.

Although lithium ion batteries are less toxic than lead acid and nickel-cadmium ones, their end of life has to comply with European (European Union, 2006) and United States (New York State Senate, 2010) legislations. As after their use in automotives they may mantain as much as $80 \%$ capacity, a feasible option is to reuse them for other applications such as stationary power (Heymans et al., 2014), with the advantage of multiple lifespans and a reduced environmental impact (Richa et al., 2017). Anyway, several industrial tecnologies are presently available to recycle lithium ion batteries and a scheme for the simultaneous recovery of all their components has recently been reported (Rothermel et al., 2016).

Figure 1 shows that the Periodic Table elements present in a smartphone are 29. Among them only 12 have full availability in the future (green background) while for as many as 6 there is a serious threat of supply in the next 100 years (red background). The availability and recovery of elements used in lithium ion rechargeable batteries have been previously discussed. Furthermore, several elements are necessary to guarantee high performances in the above Hi-Tech device. As many as 8 elements present in a mobile phone are "rare earth elements". According to the IUPAC definition, the 17 rare earth elements include the 15 lanthanides as well as scandium and yttrium, occurring in the same ore deposits as the lanthanides, and exhibiting similar chemical properties.

Herein the attention is focused on two key elements for smartphones performances: neodymium and indium.

For an iPhone to vibrate, for AirPods to play music, for wind turbines to generate power and for an electric motor to spin, powerful magnets are needed. The combined neodymium-iron-boron magnet is the most powerful type of permanent magnet ever created, particularly suitable for miniature applications.

Neodymium occurs in ores such as monazite (Wikipedia contributors, 2019b) and bastnäsite (Wikipedia contributors, 2019a) containing small amounts of rareearth metals. The main mining areas are in China. Although its reserves are estimated to be about eight million tons, neodymium is presently responsible for most, if not all, of the growth in rare earth demand. The main mining areas are in China. The geopolitical concentration of $\mathrm{Nd}$ and its rapid demand growth 
represent a risk for future global supply.

Indium is essential for touch-screen devices whose glass is covered by an indium oxide grid. When the finger touches the screen, an extremely low charge allows identification of the contact point. Indium is produced mainly as a byproduct of zinc ores geographically concentrated in China, Peru, Canada, Australia and the United States. Indium reserves are estimated to be 15,000 tons and its production reached about 700 tons in 2013 (Lokanc et al., 2015). About half of primary refined indium is produced in China. Indium is one of the scarcer elements in term of average abundance in the Earth's crust and its growing demand poses the risk that indium prices could be much higher than current and recent prices. For this reason in the Figure indium has a red background, indicating a serious threat of supply in the next 100 years. For a comprehensive report on indium future availability see Lokanc et al. (2015).

A very important issue in circular economy is recycling, at present often inefficient due to the limits imposed by social behaviour, product design, and recycling technology. Scientists istinctively think of technology as the major issue, but social and cultural aspects are at least as important, perhaps more than so (Oswald and Reller, 2011). Waste such as papers, cans, bottles are taken to designated places and treated by well established procedures. For refrigerators, computers, mobile phones or automobiles the recycling procedures are diverse and depend on the development of new technology. The more diverse are the materials providing their high performances, the more difficult it is to recycle preserving the resources needed to make them work in the first place. Manual disassembly of discarded electronics is not economically feasible in industrialized countries, but may be advantageous in emerging economies. On the other hand, innovative technologies are needed for end-processing in industrialized countries. An interesting example attempting to combine the above economic requirements is provided in Peru, where single materials of discarded computers such as copper, steel and aluminum are recycled domestically, while more complex and valuable printed circuit boards are exported to Germany (Kahhat and Williams, 2009). The recycling technology has achieved an enormous development in recent years. The recovery of battery components is presently achieved and literature is providing improved recovery schemes (Rothermel et al., 2016). The use of Hi-Tech waste as "Urban Mines" of precious metals has recently been proposed (Serpe, 2019). For metals the so called economy model at Christmas' tree is particularly suitable as for the same source of a certain metal different lines of industrial use can be followed. An excellent paper on metal recycling (Reck and Graedel, 2012) provides a comprehensive account in the field including the current status, the recycling technology and future challenges. The above paper reports a Periodic Table, defined by a United Nations panel, providing the global estimates of end-of life recycling rates for 60 metals and metalloids. The recycling rate for the common used "basic metals" ( $\mathrm{Al}, \mathrm{Ti}, \mathrm{Cr}, \mathrm{Mn}, \mathrm{Fe}, \mathrm{Co}, \mathrm{Ni}$, $\mathrm{Cu}, \mathrm{Zn}, \mathrm{Nb}, \mathrm{Rh}, \mathrm{Pd}, \mathrm{Ag}, \mathrm{Au}, \mathrm{Pb}$ ) is above 50\%. On the other hand among "specialty metals" improving the performance of Hi-Tech products, little if not none is currently being recycled. After millennia in which products were made using 
a small bunch of elements, in the past decades modern technology is using almost every element in the Periodic Table, but often only once. A recent editorial points out the nanotechnology facets of the Periodic Table exploiting elemental combinations to produce new advanced nanomaterials (Goodilin et al., 2019). It is interesting to note that presently $\mathrm{Hi}$-Tech devices are manifactured with the best possible technologies we can devise, but are generally recycled using relatively basic approaches. Although the recent increase in rare earth prices has stimulated research in recycling technologies for specialty metals, the situation is far from being satisfactory. An interesting perspective would be "to involve the designers for future products in choosing materials combinations with recycling in mind" (Reck and Graedel, 2012). In this context it is desirable that universities, corporations and governments will work together to stimulate research on improved recycling technologies by regulatory and financial initiatives aimed at facing the challenge of balancing economic and environmental sustainability.

\section{Conclusions}

The genius of Mendeleev conceived an outstanding system to understand and classify the elements, demonstrating human mind's capability to investigate the deepest nature of matter. In the past 150 years the Periodic Table had an enormous impact on the scientific progress and on the improvement of mankind life conditions and societal welfare. However, the increasing recognition of the limited resources of our planet, requiring a change of paradigm from linear economy to circular economy, suggests to revisit the Periodic Table from a different perspective.

In order to comply with the rules of circular economy (i.e. careful use of the planet's resources, sustainable production processes, limited waste production, waste recovery), additional information is needed to complement the traditional Periodic Table data.

An estimate of the elements future global supply requires the knowledge of market factors such as their abundance in the Earth's crust, the likehood of rapid demand growth and limitations to expanding production capacity, as well as of the political risks related to the concentration of supply in a few giant or politically unstable countries. Another important information is the sustainability of refining and of industrial productions based on green chemistry principles. Last but not least, the elements recycling possibility and waste valorization as raw materials for new production.

Scientists, followed slowly by institutions and manifacturers, are moving towards the implementation of a virtuous circular economy model, which cannot be achieved without the collaboration of the citizens. The motto for all of us can be summarized by the well known three R: Reduce, Re-use, Recycle. 


\section{References}

Baldé, C. P., Forti, V., Gray, V., Kuehr, R., and Stegmann, P. (2017). The Global E-waste Monitor (United Nations University (UNU), International Telecommunication Union (ITU) and International Solid Waste Association (ISWA), Bonn/Geneva/Vienna).

Cannizzaro, S. (1858). Lettera del prof. Stanislao Cannizzaro al prof. S. De Luca; Sunto di un corso di filosofia chimica, fatto nella R. Università di Genova. Il Nuovo Cimento (1855-1868) 7(1), 321. doi:10.1007/BF02827711.

European Chemical Society (2019). International Year of the Periodic Table of the Elements, IYPT2019. URL https://www . euchems . eu/euchems-periodic-table/.

European Union (2000). Directive 2000/53/EC of the European Parliament and of the Council of 18 September 2000 on end-of life vehicles - Commission Statements. Official Journal of the European Communities 269, 34. URL http://data. europa.eu/eli/dir/2000/53/oj.

European Union (2006). Directive 2006/66/EC of the European Parliament and of the Council of 6 September 2006 on batteries and accumulators and waste batteries and accumulators and repealing Directive 91/157/EEC (Text with EEA relevance). Official Journal of the European Communities 266, 1. URL http: //data. europa.eu/eli/dir/2006/66/oj.

Goodilin, E. A., Weiss, P. S., and Gogotsi, Y. (2019). Nanotechnology Facets of the Periodic Table of Elements. ACS Nano 13(10), 10879. doi:10.1021/acsnano.9b06998.

Heymans, C., Walker, S. B., Young, S. B., and Fowler, M. (2014). Economic analysis of second use electric vehicle batteries for residential energy storage and load-levelling. Energy Policy 71, 22. doi:https: / / doi.org/10.1016/j.enpol.2014.04.016.

Jaffe, S. (2017). Vulnerable Links in the Lithium-Ion Battery Supply Chain. Joule 1(2), 225. doi:10.1016/j.joule.2017.09.021.

Kahhat, R. and Williams, E. (2009). Product or Waste? Importation and End-of-Life Processing of Computers in Peru. Environmental Science \& Technology 43(15), 6010. doi:10.1021/es8035835.

Lee, J., Seo, D.-H., Balasubramanian, M., Twu, N., Li, X., and Ceder, G. (2015). A new class of high capacity cation-disordered oxides for rechargeable lithium batteries: Li-Ni-Ti-Mo oxides. Energy Environ. Sci. 8, 3255. doi:10.1039/C5EE02329G.

Levi, P. (1987). Il sistema periodico. In Opere, volume 1 (Einaudi, Torino).

Lokanc, M., Eggert, R., and Redlinger, M. (2015). The Availability of Indium: The Present, Medium Term, and Long Term. National Renewable Energy Lab. (NREL) report (NREL/SR-6A20-62409). doi:10.2172/1327212.

Mendeleev, D. I. (1869). Sootnoshenie svojstv s atomnym vesom jelementov. Zhurnal Russkogo himicheskogo obshhestva 1, 60.

Nansai, K., Nakajima, K., Kagawa, S., Kondo, Y., Suh, S., Shigetomi, Y., and Oshita, Y. (2014). Global Flows of Critical Metals Necessary for Low-Carbon Technologies: The Case of Neodymium, Cobalt, and Platinum. Environmental Science \& Technology 48(3), 1391. doi:10.1021/es4033452.

New York State Senate (2010). The NYS Rechargeable Battery Recycling Act. In Environmental Conservation Law, pages Article 27, Title 18. URL https://www. 
dec.ny.gov/docs/materials_minerals_pdf/batterylaw.pdf.

Olivetti, E. A., Ceder, G., Gaustad, G. G., and Fu, X. (2017). Lithium-Ion Battery Supply Chain Considerations: Analysis of Potential Bottlenecks in Critical Metals. Joule 1(2), 229. doi:10.1016/j.joule.2017.08.019.

Oswald, I. and Reller, A. (2011). E-Waste: A Story of Trashing, Trading, and Valuable Resources. GAIA - Ecological Perspectives for Science and Society 20(1), 41. doi:doi:10.14512/gaia.20.1.9.

Reck, B. K. and Graedel, T. E. (2012). Challenges in Metal Recycling. Science 337(6095), 690. doi:10.1126/science.1217501.

Richa, K., Babbitt, C. W., Nenadic, N. G., and Gaustad, G. (2017). Environmental trade-offs across cascading lithium-ion battery life cycles. The International Journal of Life Cycle Assessment 22(1), 66. doi:10.1007/s11367-015-0942-3.

Rothermel, S., Evertz, M., Kasnatscheew, J., Qi, X., Grützke, M., Winter, M., and Nowak, S. (2016). Graphite Recycling from Spent Lithium-Ion Batteries. ChemSusChem 9(24), 3473. doi:10.1002/cssc.201601062.

Serpe, A. (2019). Hi-Tech waste as "Urban Mines" of precious metals: new sustainable recovery methods. Substantia 3(1), 61. doi:10.13128/Substantia-607.

Wikipedia contributors (2019a). Bastnäsite. In Wikipedia, The Free Encyclopedia. URL https://en.wikipedia.org/w/index.php?title=Bastn\%C3\%A4site\& oldid=894262048.

Wikipedia contributors (2019b). Monazite. In Wikipedia, The Free Encyclopedia. URL https://en.wikipedia.org/w/index.php?title=Monazite\&oldid= 931870312.

Yabuuchi, N., Takeuchi, M., Nakayama, M., Shiiba, H., Ogawa, M., Nakayama, K., Ohta, T., Endo, D., Ozaki, T., Inamasu, T., Sato, K., and Komaba, S. (2015). High-capacity electrode materials for rechargeable lithium batteries: $\mathrm{Li}_{3} \mathrm{NbO}_{4}$-based system with cation-disordered rocksalt structure. Proc. Nat. Acad. Sci. 112(25), 7650. doi:10.1073/pnas.1504901112. 